\title{
Presença de Ocratoxina A em Vinhos
}

Priscilla Silva de Abreu (I), Luisa Freire (I), Michelle Ferreira Terra (I), Livia Martinez Abreu Soares Costa (I), Luis Roberto Batista (I)

(I) UFLA - Universidade Federal de Lavras (Câmpus Universitário, Caixa Postal 3037, CEP 37200-000, Lavras/MG)

\section{Resumo}

Diversas pesquisas têm demonstrado uma relação inversa entre o moderado consumo de vinho, morbidade e mortalidade por doenças cardiovasculares, redução de risco de câncer e outras causas de mortalidade, porém a presença de substâncias tóxicas como as micotoxinas podem comprometer a qualidade e a segurança do produto. A cada ano nota-se um expressivo aumento no consumo de vinhos no Brasil e no mundo, portanto é de extrema importância que a qualidade destes produtos seja avaliada para minimizar os possíveis danos que a ingestão de micotoxinas, em especial, da Ocratoxina A, podem causar. O objetivo deste estudo foi avaliar 38 amostras de vinhos nacionais e importados ( 27 tintos, 7 brancos, 2 rosés e 2 fortificados) para verificar a presença ou não de ocratoxina $\mathrm{A}$, bem como analisar se os níveis de contaminação estavam dentro dos limites que são aceitos pela legislação. As análises foram realizadas pelo método de cromatografia líquida de alta eficiência (HPLC). Os limites de detecção e quantificação de OTA foram de 0,16 e $0,56 \mu \mathrm{g} / \mathrm{kg}$ respectivamente. As amostras analisadas $(36,84 \%)$ apresentou contaminação com ocratoxina A, sendo todas as amostras importadas. A contaminação nos vinhos foi relativamente baixa, com exceção de duas amostras provenientes da França e da Argentina, para as quais foram obtidos valores de 2,47 e 2,78 $\mu \mathrm{g} / \mathrm{L}$, respectivamente. Do total de amostras contaminadas, $85,71 \%$ apresentaram níveis de contaminação por ocratoxina A inferiores a $2 \mu \mathrm{g} / \mathrm{L}$. Todos os vinhos onde a presença de ocratoxina A foi detectada eram tintos, sendo que os vinhos brancos e rosé não apresentaram contaminação. Os

\footnotetext{
Referência:

Priscilla Silva de Abreu, Luisa Freire, Michelle Ferreira Terra, Livia Martinez Abreu Soares Costa, Luis Roberto Batista. Presença de Ocratoxina A em Vinhos. In: Anais do 12을 Congresso Latinoamericano de Microbiologia e Higiene de Alimentos - MICROAL 2014 [= Blucher Food Science Proceedings, num.1, vol.1]. São Paulo: Editora Blucher, 2014.

DOI 10.5151/foodsci-microal-085
} 
resultados deste estudo indicam que a maior parte dos vinhos avaliados apresentava-se seguros para o consumo, com exceção apenas de duas amostras importadas. Todos os produtos nacionais estudados, bem como as amostras de vinhos brancos e rosé apresentaram concentrações abaixo dos limites máximos tolerados para esta toxina em vinhos.

Palavras-Chave: Ocratoxina A, Vinho, HPLC Agência de Fomento: Cnpq, Fapemig 